\title{
Cyclone vulnerability assessment of cuddalore coast in Tamil Nadu, India using remote sensing, and GIS
}

\author{
Subbarayan Saravanan ${ }^{1, *}$, Jacinth Jennifer $\mathrm{J}^{2}$, Leelambar $\operatorname{Singh}^{2}$, and Abijith $\mathrm{D}^{2}$ \\ ${ }^{1}$ Assistant Professor, Department of Civil Engineering, National Institute of Technology Tiruchirappalli, Tamil Nadu, India \\ ${ }^{2}$ Research Scholar, Department of Civil Engineering, National Institute of Technology Tiruchirappalli, Tamil Nadu, India
}

\begin{abstract}
Over the years, cyclones have left a deep and dark footprint on the coastal region of the Cuddalore district in southeast India, which was one of the worst affected districts in the mainland. These disasters over the past several years have revealed the differential impacts due to social structure, economic conditions, and level of infrastructure. Therefore, there is a need for strategies to address the aspects of socioeconomic and infrastructural vulnerability. Cuddalore district is one of the most vulnerable districts for Cyclone. The present study investigates the vulnerability of eastern coastal states of India from potential cyclones using Remote Sensing and GIS. Mapping of cyclone vulnerability zone on 1:50000 scale along the Tamil Nadu coast has been carried out using Remote Sensing and GIS techniques with six physical parameters such as elevation, wind speed, historical cyclone event significant wave height, probable maximum precipitation, and Landuse and Landcover. The regular rank and weight method have been used to integrate the above parameters to achieve the cyclone vulnerability zone map. The resultant cyclone vulnerability zone map has been divided into five cyclone vulnerability categories, namely very high, high, moderate, low, and very low. The output of the study showed significant results, which reflect that the entire northern coastal taluks come under very high cyclone vulnerability zone whereas central and southern coastal taluks fall under high to low cyclone vulnerability zone. This information would serve useful in advanced planning to minimize associated cyclone losses and reduce threats to future coastal development.
\end{abstract}

\section{Introduction}

Tamil Nadu coast has been experiencing frequent cyclone disasters which claim significant losses and damages. The history of coastal disaster around the globe due to nature's fury has provided powerful reminders of the vulnerability of coastal regions. The recent decade has witnessed not only an increase in the frequency but also the intensity and duration of cyclones [1]. Therefore, it is time to generate various means and methods to map the vulnerability of cyclones, so that the impact of the disaster can be minimized. In this direction, there have been many attempts, and the present study is based on integrating the cyclone vulnerability zone map and appropriate coastal zone management plan.

India is mostly affected by the seasonal tropical cyclones during the southwest monsoon (JuneSeptember), and most of the east coast is affected by the northeast monsoon (October- December) [2] and hence, is highly vulnerable to storm surge events. It has been reported that from the year 1737 alone, more than 10,000 human lives lost during each event of major storm surges [3]. Therefore, extensive studies were carried out in the areas of individual hazards such as storms, cyclones, by several researchers in the North Indian Ocean, Arabian Sea and the Bay of Bengal shores. [4][5][6]. Similar studies have been carried out in countries like Taiwan where the typhoon approach causes strong winds and low atmospheric pressure to create a storm surge. This surge may result in severe damage to coastal areas, especially to the low-lying lands near river mouths. The extent of severity is due to the double effects of the river floods by typhoon-brought rains; and the backward uplifting seawater floods from storm surges [7].

In this study, mapping of cyclone vulnerability zone on 1:50000 scale along the Tamil Nadu coast has been carried out using Remote Sensing and GIS techniques with the six physical parameters, namely elevation, wind speed, historical cyclone event, land use/land cover, probable maximum precipitation. The WSM model has been used to integrate the above parameters to achieve the cyclone vulnerability zone map. Cyclone vulnerability zone map has been divided into five cyclone vulnerability categories, namely very high, high, moderate, low, and very low.

\section{Study area and data used}

Cuddalore district is in the south-east side of India, on the shores of Bay of Bengal. Analysis of changes along the shoreline using the information extracted from the tellite imageries between the years 1972 and 2011 indicated that the average net rate of shoreline change was $+0.15 \mathrm{~m}$ per year. Of the total length of $42 \mathrm{~km}$ studied for shoreline changes, about $40.5 \%$ of the coastline is accreting, while, $15.72 \%$ of the coastline is medium to highly eroded and $18.23 \%$ is classified under

Corresponding author: ssaravanan@nitt.edu 
low erosion zone. The flood hazard mapping study undertaken for a stretch of $\sim 14 \mathrm{~km}$ along the Cuddalore coastline for 1-in-100-year extreme flood level, including local mean sea level and global sea-level rise indicated maximum inundation level to be $\sim 3.62 \mathrm{~m}$ from MSL for the Cuddalore coastal region [8]. Assessment of multi-hazard vulnerability along the Cuddalore coast suggests that the river system act as the flooding corridors that carry larger and longer interlard inundation.

The cyclone vulnerability of Tamil Nadu and Puducherry coast has been assessed at Taluk level by considering six parameters (Table 1), and those were (i) elevation, (ii) wind speed, (iii) land use/land cover, and (iv) historical cyclone event, (v) probable maximum precipitation, and (vi) significance of wave height. The geospatial databases and maps of these parameters were prepared in GIS environment (ArcGIS software) on 1: 50,000 scales. The importance and extraction of the selected parameters have been discussed concerning the cyclone vulnerability as shown in Fig. 1.



Fig. 1. Location map of Cuddalore district of Tamil Nadu

\section{Methodology}

The methodology adopted for the Cyclone Vulnerability zonation for Cuddalore district is summarized in the flowchart as shown in Fig. 3. Mapping of cyclone vulnerability zone was carried using the Remote Sensing and GIS techniques with the six physical parameters, as mentioned above. The study utilized the satellite data of Landsat ETM+ of April 2010 (Path 142 Row 52) for generation of LULC using hybrid classification technique (supervised and unsupervised) and ground truthing. Carto DEM was used to extract the elevation variation map. Rainfall data, wind speed data were also collected from TNAU weather portal and PWD for the cyclonic storm period. Significant wave height was collected from the Cuddalore and Nagapattinam port. This point data was interpolated and assigned to each block in the study area. Historical cyclone and frequency of cyclone data were obtained from the NDMA report and assigned for each block.

The regular rank and weight method were then used to integrate the parameters to achieve the cyclone vulnerability map. Table 1 . shows the different vulnerability classes. Based on the intensity, these were further divided into five categories like very low, low, moderate, high and very high for different cyclone parameters [9]. All the parameter layers were converted into $30 \times 30 \mathrm{~m}$ grid as per its rating values. Weights of each influencing factors were multiplied in the raster environment, and the composite Cyclone Vulnerability map was generated using the overlay technique.

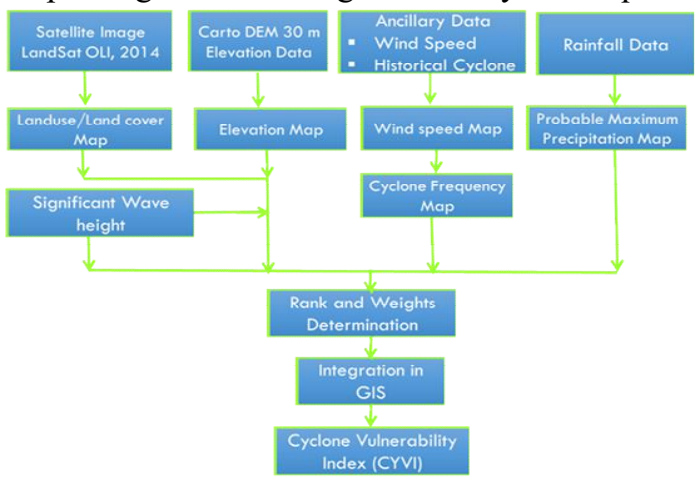

Fig. 2. The Methodology of cyclone vulnerability mapping

Table 1.Vulnerability Class and Weight Values Used For Cyclone Vulnerability

\begin{tabular}{|c|c|c|c|c|c|c|}
\hline \multirow[t]{2}{*}{ Factors } & \multicolumn{5}{|c|}{ Vulnerability Class } & \multirow{2}{*}{$\begin{array}{c}\text { Weig } \\
\text { ht }\end{array}$} \\
\hline & $\begin{array}{l}\text { Very } \\
\text { low }\end{array}$ & low & $\begin{array}{l}\text { Mod } \\
\text { erate }\end{array}$ & high & $\begin{array}{l}\text { Very } \\
\text { high }\end{array}$ & \\
\hline Rating & 1 & 3 & 5 & 7 & 10 & \\
\hline $\begin{array}{c}\text { Elevation } \\
(\mathrm{m})\end{array}$ & $>125$ & $\begin{array}{l}75- \\
125 \\
\end{array}$ & $\begin{array}{l}35- \\
75\end{array}$ & $2-35$ & $<2$ & 20 \\
\hline $\begin{array}{c}\text { Wind } \\
\text { speed } \\
(\mathrm{km} / \mathrm{hr})\end{array}$ & $<68$ & $\begin{array}{l}68- \\
111\end{array}$ & $\begin{array}{c}111- \\
150\end{array}$ & $\begin{array}{c}150- \\
168\end{array}$ & $>168$ & 25 \\
\hline $\begin{array}{c}\text { Landuse } \\
\text { /Land } \\
\text { Cover }\end{array}$ & $\begin{array}{c}\text { All } \\
\text { other } \\
\text { classe } \\
\text { s }\end{array}$ & $\begin{array}{c}\text { Fall } \\
\text { ow } \\
\text { land }\end{array}$ & $\begin{array}{l}\text { Plant } \\
\text { ation }\end{array}$ & $\begin{array}{l}\text { Agric } \\
\text { ultura } \\
1 \text { land }\end{array}$ & $\begin{array}{c}\text { Settle } \\
\text { ment } \\
\mathrm{s}\end{array}$ & 10 \\
\hline $\begin{array}{l}\text { Historical } \\
\text { Cyclone } \\
\text { (No) }\end{array}$ & $<2$ & $6-10$ & $\begin{array}{l}11- \\
15\end{array}$ & $\begin{array}{c}16- \\
20\end{array}$ & $>20$ & 10 \\
\hline SWH & $<0.5$ & $\begin{array}{c}0.5- \\
1 \\
\end{array}$ & $1-.25$ & $<0.5$ & $>1.5$ & 15 \\
\hline $\begin{array}{l}\text { PMP } \\
(\mathrm{cm})\end{array}$ & $1-5$ & $5-15$ & $\begin{array}{l}15- \\
25 \\
\end{array}$ & $1-5$ & $>35$ & 20 \\
\hline
\end{tabular}

\section{Input parameters generation}

\subsection{Elevation}

Elevation refers to the height of an object on the earth's surface from Mean Sea Level (MSL). From the past cyclone data analysis over the area, it was found that mountain/hills are working like as a barrier for cyclone wind, they protect all the areas/land that is behind of them from the effect of cyclone wind. The elevation dataset was obtained from CartoDEM $30 \mathrm{~m}$ resolutions. In the present study, elevation was considered as an important parameter for mapping of cyclone vulnerability wherein the elevation dataset of the study area has been divided into five cyclones vulnerable zone based on the height of the land, such as very high $(<$ $2 \mathrm{~m})$, high $(2-35 \mathrm{~m})$, moderate $(35-75 \mathrm{~m})$, low $(75-125 \mathrm{~m})$, 
and very low (>125m) cyclone vulnerable zone. Fig. 3. depicts the elevation map of the region.

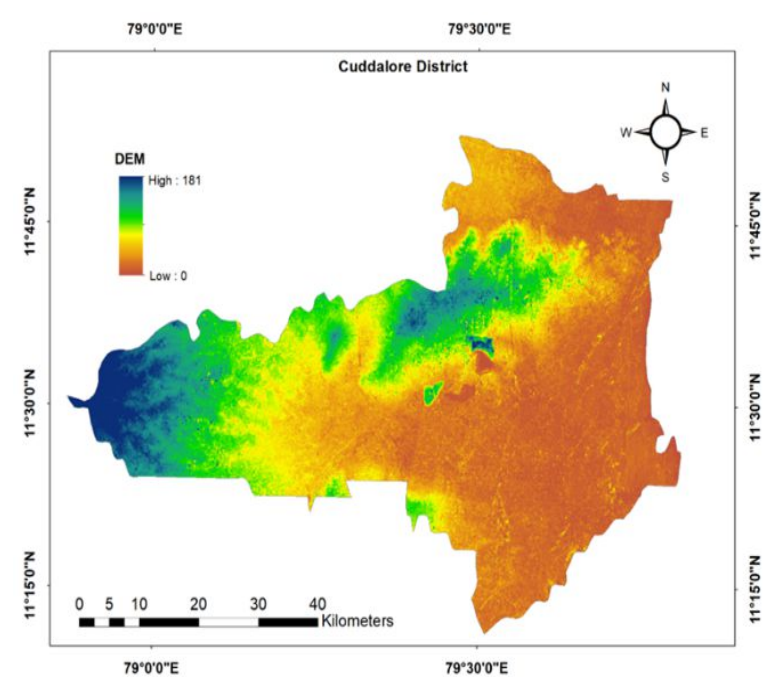

Fig. 3. Digital Elevation Model of the Study area

\subsection{Wind speed}

Wind speed in the region is variable due to the topography, land use and region of landfall of the cyclone. The historical wind speed data was collected from the Public Works Department and Automatic Weather Station (AWS) located in each block in the Cuddalore district at the time of cyclone landfall. The wind speed map shows a gradual decrease in the intensity of winds from the coastal to highland. Fig.4 shows the spatial variation of the wind speed. The zone is divided into five cyclone vulnerability zones based on the wind speed information provided by the wind speed map, i.e. very high $(>168 \mathrm{~km} / \mathrm{h})$, high $(150-168 \mathrm{~km} / \mathrm{h})$, moderate $(111-150 \mathrm{~km} / \mathrm{h})$, low $(68-111 \mathrm{~km} / \mathrm{h})$, and very low $(<68 \mathrm{~km} / \mathrm{h})$ zone.

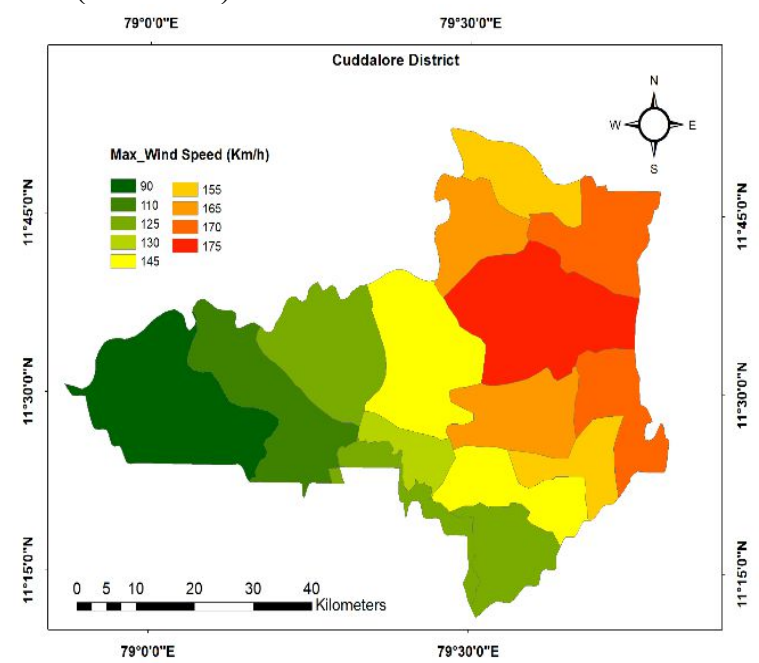

Fig. 4. Wind speed map of the Study area

\subsection{Land use/land cover}

Cyclonic activity impacts the property, utilities, and the human population along with various land use/land cover. The cyclone disasters have been observed by analyzing historical cyclones over the study area. The land use/land cover map was extracted from Landsat 8 OLI/TIRS satellite image (2015) in the GIS environment (Fig. 5.). The land use/land cover classes have been divided into five cyclone vulnerability zone based on the potentiality of the land use/land cover classes towards cyclone disaster, such as very high (Settlements, builtups), high (Agriculture/Crops), moderate (Plantation, Saltpan), low (Wasteland, Fallow land), and very low (all other classes) zone.

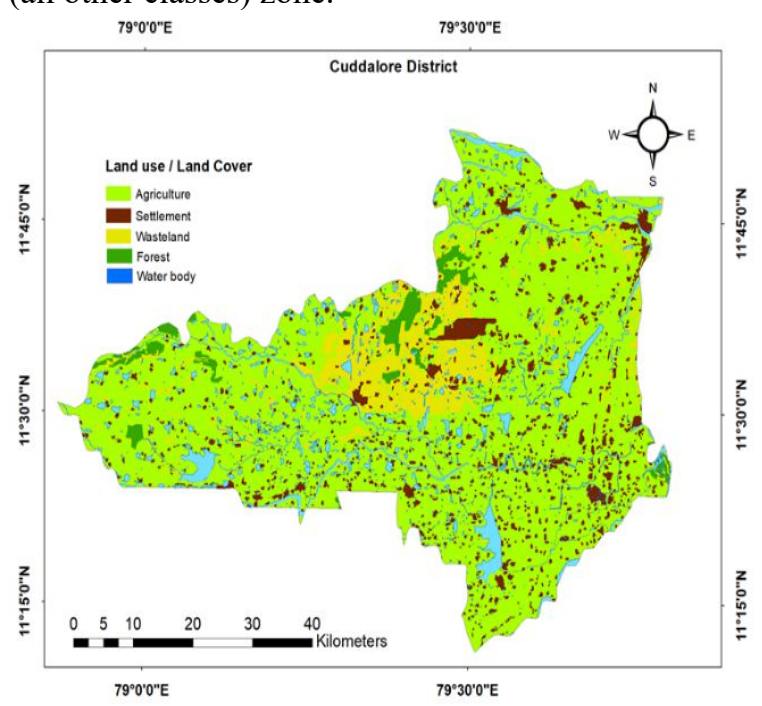

Fig. 5. Land use/ Landover map of the Study area

\subsection{Historical cyclones}

Historical Cyclone tracks of the region were acquired from NOAA webpage. The analyses of historical cyclones for each taluk have been carried out using point in polygon method that reveals tracks of landfall on the taluk. The taluk has been divided into the following cyclone prone zone based on the number of cyclone passing tracks, such as very high $(>20)$, high (16-20), moderate $(11-15)$, low $(6-10)$, and very low $(<2)$ zone. Fig. 6. depicts the cyclone tracks, and Fig 7 portrays the cyclone frequency map of the study area.

\subsection{Probable maximum precipitation}

Probable maximum precipitation (PMP) is a theoretical concept that is widely used by hydrologists to arrive at estimates for probable maximum flood (PMF) that find use in planning, design, and risk assessment [10]. Heavy rainfall is associated with tropical cyclones. As a result, the precipitation pattern of the study area strongly influences to intensify the impacts of a tropical cyclone. To map precipitation intensity, the daily precipitation data (1950-2015) collected from the Indian Metrological Department (IMD) and data from AWS stations were used in this study. The data regarding PMP and the distribution of ratings were obtained from the National Disaster Management Authority. Fig 8 shows the spatial variation of 100 year return period PMP over Cuddalore district. 


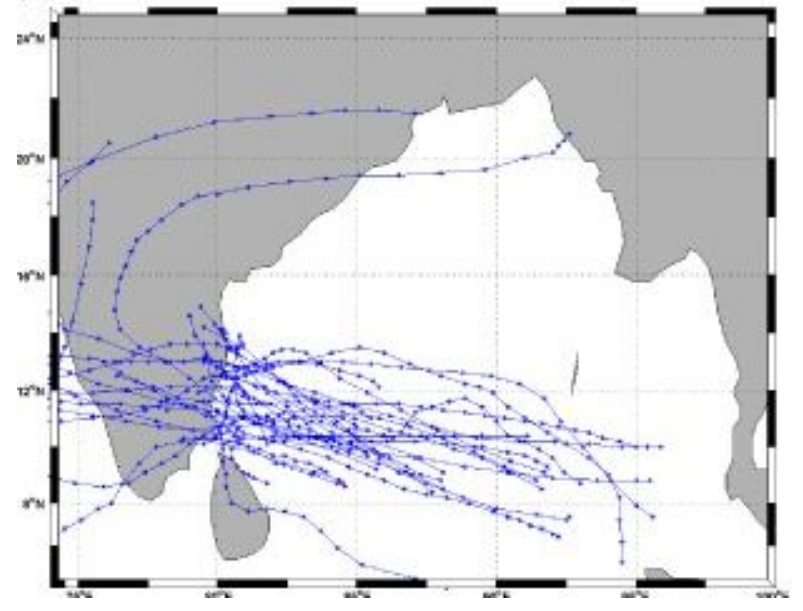

Fig. 6. Historical cyclone track $(1842-2014)$ of the study area (NOAA)

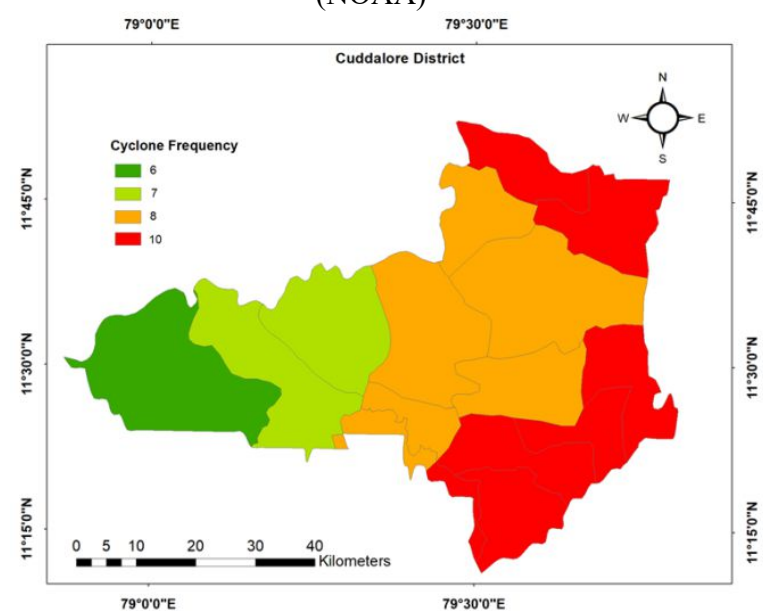

Fig. 7. Cyclone frequency map of the study area

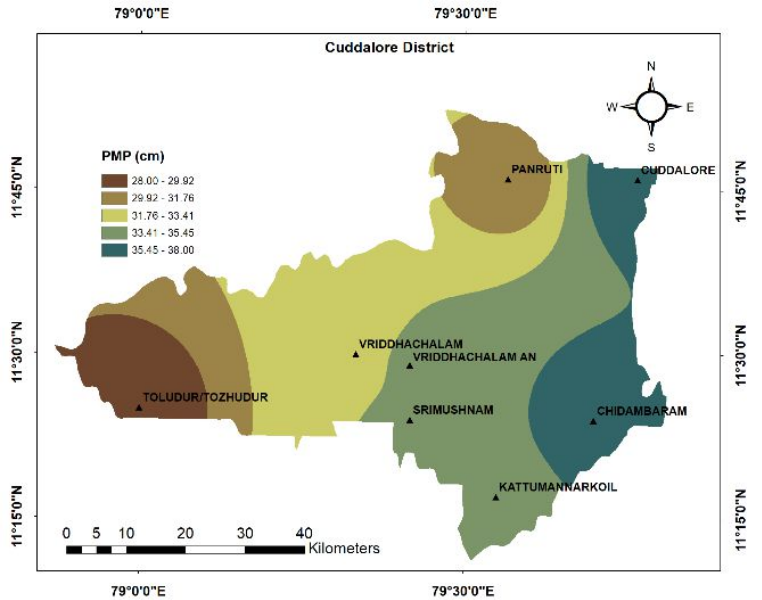

Fig. 8. Probable maximum precipitation map of the study area

\subsection{Significant wave height}

Significant wave height is defined as the average height of the highest one-third waves in a wave spectrum. Its value roughly approximates to visually observed wave height. The data was obtained from the Indian National Centre for Ocean Information Services (INCOIS). The following Fig.9 shows the data extracted for the Bay of Bengal area.

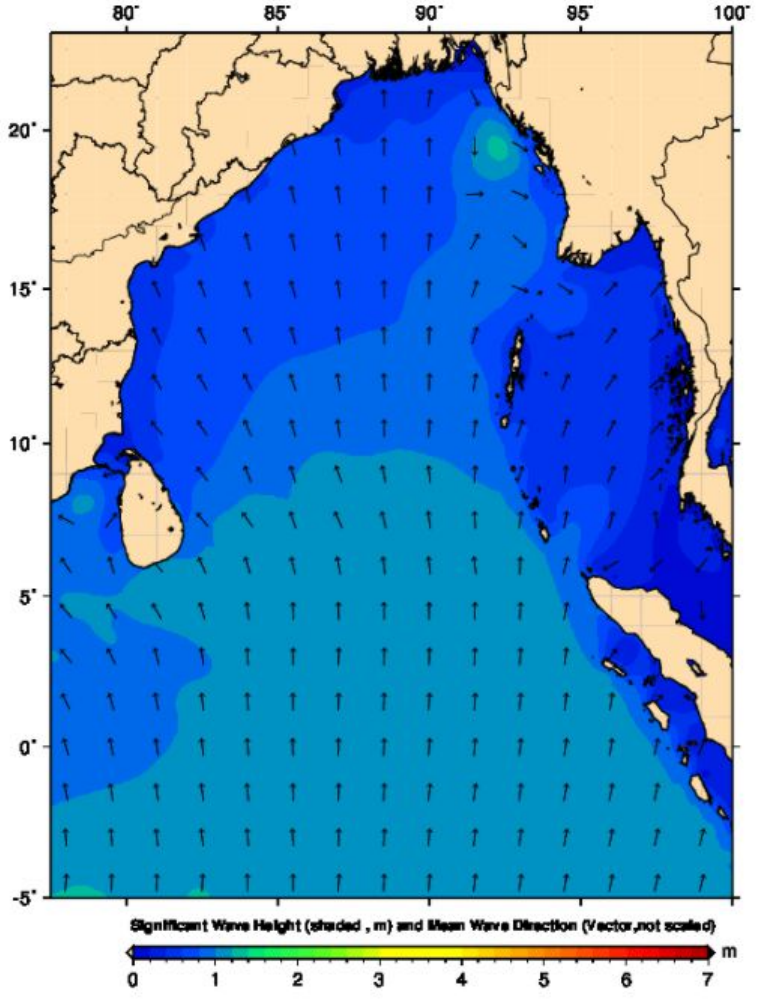

Fig. 9. Significant wave height for the Bay of Bengal

\section{Results and discussions}

Reviewing the data from IMD, it can be significantly noted that the northern Tamil Nadu coast (from Vedaranniyam to Pulicat Lake), is highly prone to cyclones and depressions when compared to the southern part of Tamil Nadu (from Kanniyakumari to Vedaranniyam). Moreover, the present study area, Cuddalore, falls on the Northern coast of Tamil Nadu. IMD has tracked the past occurrences of cyclones in the state of Tamil Nadu and has broadly classified all the tracks into three, namely depression, cyclonic storm, and severe cyclonic storm. This classification is primarily based on the impact of the cyclone and several other parameters. IMD observed 98 tracks from the period of 1891 to 2013 and was distributed into different zones. It was found that among these 98 tracks, 44 were depressions, 25 were cyclonic storms and 29 were severe cyclonic storms. Furtherly, these tracks were again classified into two divisions based on the landfall about the state of Tamil Nadu. The division was made based on geographic location for northern and southern coasts of Tamil Nadu where the cyclones made the landfall. It was seen that in the Northern coast 23 severe cyclonic storms, 24 cyclonic storms, and 34 depressions made landfall and only 6 severe cyclonic storms, 1 cyclonic storm, and 10 depressions crossed the southern Tamil Nadu coast.

Also from the cyclone track density calculations (per sq.km), it can be derived that the Northern part of Tamil $\mathrm{Nadu}$ is more affected by cyclones than the southern part. It is primarily due to the physiographic location of Sri Lanka, and hence, most of the cyclones formed in the Bay of Bengal are deflected towards north because of Sri 
Lanka. In this regard, it could be concluded that the northern Tamil Nadu coast becomes more affected by the cyclones compared to the southern coast.

In the present study, the cyclone vulnerability zone was divided into five vulnerability classes, such as very low (1), low (3), moderate (5), high (7), and very high (10) as shown in Table 1 . The result of cyclone vulnerability zone (Fig. 10.) shows that the very low to very high cyclone vulnerable areas constitute about $13.6022 \%, \quad 24.6801 \%, \quad 22.5682 \%, \quad 22.8833 \%$, and $16.2662 \%$ of the area respectively. The data is shown in Table 2. The data reveals that most of the area falls under the category of Low or Moderate vulnerability class. Moreover, only $16 \%$ of the area is under very highly affected zones.

The cyclone vulnerability map (Fig. 10.) clearly shows that the eastern side of Cuddalore facing the Bay of Bengal is very highly affected and gradually the vulnerability decreases progressively from east to west.

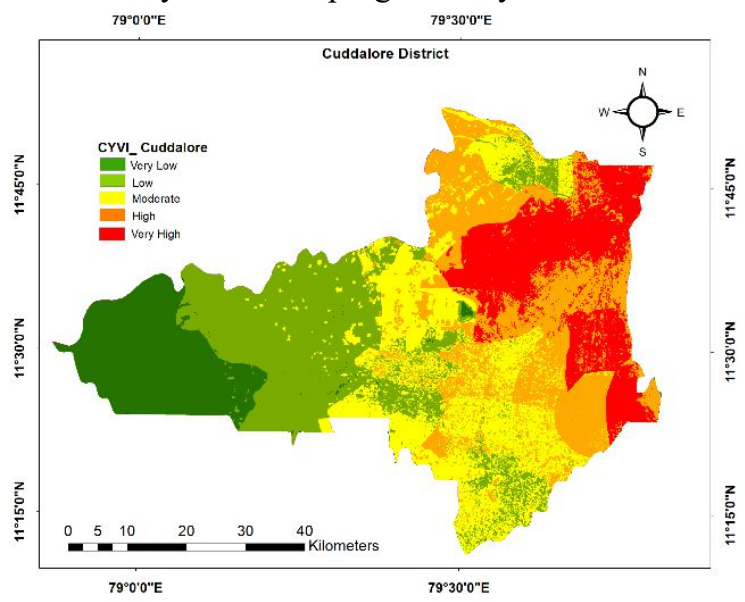

Fig. 10. Map Showing the Cyclone Vulnerability Zone of Cuddalore District of Tamil Nadu

Table 2. Cyclone Vulnerability Zone of Cuddalore District of Tamil Nadu

\begin{tabular}{|c|c|c|}
\hline Vulnerability & Area $\left.\mathbf{( k m}^{\mathbf{2}}\right)$ & $\begin{array}{c}\text { Percentage of } \\
\text { Area }\end{array}$ \\
\hline Very Low & 490.866 & 13.6 \\
\hline Low & 890.638 & 24.6 \\
\hline Moderate & 814.424 & 22.5 \\
\hline High & 825.794 & 22.8 \\
\hline Very High & 587.004 & 16.2 \\
\hline Total & 3608.73 & 100.0 \\
\hline
\end{tabular}

\section{Conclusions}

In the present study, the Cyclone vulnerability assessment has been carried out using six variables namely, elevation, land use, wind speed, historical cyclone, probable maximum precipitation, significant wave height. These parameters were integrated using GIS, and a geospatial model has been made. This was used for the extraction of cyclone vulnerability areas. The cyclone vulnerability map has been categorized into five different vulnerability zones, namely very low, low, moderate, high, and very high. From this map, it can be concluded that the coastal areas of Cuddalore district are more vulnerable due to cyclone than the interior coastal areas of the district.

The Assessment of multi-hazard vulnerability along the Cuddalore coast suggests that river systems act as the flooding corridors that carry larger and longer interlard inundation. This further causes alterations in the elevation, which can further lead to the changes in the geophysical characteristics of the coast. As the study suggests, elevation also can act as an important parameter in determining the landing of a cyclone; inundation may further lead to severe consequences in the coast of Tamil Nadu.

The present approach discusses the use of Remote Sensing and GIS techniques in estimating the cyclone vulnerability. This will be of a crucial use for the coastal authorities and Government for preparing a management strategy for the highly vulnerable coastal areas. Furtherly the study can be enhanced by incorporating other atmospheric and environmental parameters like the ocean temperature, solar radiation, humidity, and meteorological parameters. This can lead to an increase in efficiency of assessing the vulnerability of coastal areas during the occurrences of a cyclone.

\section{References}

1. Chavan, Sagar Rohidas, and V. V. Srinivas. "Probable maximum precipitation estimation for catchments in Mahanadi river basin." Aquatic Procedia 4, 892-899 (2015)

2. Chen, Yi-Ru, Chao-Hsien Yeh, and Bofu Yu. "Integrated application of the analytic hierarchy process and the geographic information system for flood risk assessment and floodplain management in Taiwan." Natural Hazards 59.3, 1261-1276. (2011)

3. Dube, S.K., Jain, I., Rao, A.D. and Murty, T.S, Storm surge modeling for the Bay of Bengal and the Arabian Sea. Natural Hazards, 51(1), pp.3-27.(2009)

4. Kumar, A. Arun, and Pravin D. Kunte. "Coastal vulnerability assessment for Chennai, east coast of India using geospatial techniques." Natural Hazards 64.1 853-872, (2012)

5. Mazumdar, Jublee, and Saikat Kumar Paul. "Socioeconomic and infrastructural vulnerability indices for cyclones in the eastern coastal states of India." Natural Hazards 82.3 ,1621-1643.(2016)

6. Murty, Tad S., U. Aswathanarayana, and Niru Nirupama. "Impact of coastal morphology, structure and seismicity on the tsunami surge." The Indian Ocean Tsunami. CRC Press, 53-66.(2007)

7. Rao, A.D., Chittibabu, P., Murty, T.S., Dube, S.K. and Mohanty, U.C.,. Vulnerability from storm surges and cyclone wind fields on the coast of Andhra Pradesh, India. Natural Hazards, 41(3), pp.515529.(2007) 
8. Rogelj, J., Meinshausen, M. and Knutti, R., Global warming under old and new scenarios using IPCC climate sensitivity range estimates. Nature climate change, 2(4), p.248 (2012)

9. Saxena, S., Geethalakshmi, V. and Lakshmanan, A. Development of the habitation vulnerability assessment framework for coastal hazards: Cuddalore coast in Tamil Nadu, India - a case study. Weather and Climate Extremes, 2, pp.48-57 (2013).

10. Unnikrishnan, A. S., and D. Shankar. "Are sea-levelrise trends along the coasts of the north Indian Ocean consistent with global estimates" Global and Planetary Change 57.3-4,301-307 (2007). 